\title{
Colletotrichum higginsianum Mitogen-Activated Protein Kinase ChMK1: Role in Growth, Cell Wall Integrity, Colony Melanization, and Pathogenicity
}

\author{
Wei Wei ${ }^{1}$, Ying Xiong ${ }^{2}$, Wenjun Zhu ${ }^{3 *}$, Nancong Wang ${ }^{1}$, Guogen Yang ${ }^{4}$ and Fang Peng ${ }^{3}$ \\ ${ }^{1}$ Institute for Interdisciplinary Research, Jianghan University, Wuhan, China, ${ }^{2}$ Hefei Inzyme Information Technology Co., Ltd., \\ Wuhan, China, ${ }^{3}$ College of Biology and Pharmaceutical Engineering, Wuhan Polytechnic University, Wuhan, China, ${ }^{4}$ The \\ Provincial Key Lab of Plant Pathology of Hubei Province, College of Plant Science and Technology, Huazhong Agricultural \\ University, Wuhan, China
}

OPEN ACCESS

Edited by:

Kumar Krishnamurthy, Tamil Nadu Agricultural University,

India

Reviewed by:

Biswapriya Biswavas Misra, University of Florida, USA

Pratyoosh Shukla,

Maharshi Dayanand University, India

*Correspondence:

Wenjun Zhu

82862108@qq.com

Specialty section:

This article was submitted to

Plant Biotic Interactions,

a section of the journal

Frontiers in Microbiology

Received: 08 May 2016

Accepted: 20 July 2016

Published: 03 August 2016

Citation:

Wei W, Xiong Y, Zhu W, Wang N,

Yang $G$ and Peng $F$ (2016)

Colletotrichum higginsianum

Mitogen-Activated Protein Kinase ChMK1: Role in Growth, Cell Wall Integrity, Colony Melanization, and

Pathogenicity.

Front. Microbiol. 7:1212.

doi: 10.3389/fmicb.2016.01212
Colletotrichum higginsianum is an economically important pathogen that causes anthracnose disease in a wide range of cruciferous crops. To facilitate the efficient control of anthracnose disease, it will be important to understand the mechanism by which the cruciferous crops and C. higginsianum interact. A key step in understanding this interaction is characterizing the mitogen-activated protein kinases (MAPK) signaling pathway of $C$. higginsianum. MAPK plays important roles in diverse physiological processes of multiple pathogens. In this study, a Fus3/Kss1-related MAPK gene, ChMK1, from C. higginsianum was analyzed. The results showed that the Fus3/Kss1-related MAPK ChMK1 plays a significant role in cell wall integrity. Targeted deletion of ChMK1 resulted in a hypersensitivity to cell wall inhibitors, reduced conidiation and albinistic colonies. Further, the deletion mutant was also unable to form melanized appressorium, a specialized infection structure that is necessary for successful infection. Therefore, the deletion mutant loses pathogenicity on $A$. thaliana leaves, demonstrating that ChMK1 plays an essential role in the early infection step. In addition, the ChMK1 deletion mutant showed an attenuated growth rate that is different from that of its homolog in Colletotrichum lagenarium, indicating the diverse roles that Fus3/Kss1-related MAPKs plays in phytopathogenic fungi. Furthermore, the expression level of three melanin synthesis associated genes were clearly decreased in the albinistic ChMK1 mutant compared to that of the wild type strain, suggesting that ChMK1 is also required for colony melanization in C. higginsianum.

Keywords: Colletotrichum higginsianum, MAPK, pathogenicity, cell wall integrity, growth rate

\section{INTRODUCTION}

The hemibiotrophic fungal pathogen Colletotrichum higginsianum causes anthracnose disease. The disease typically manifests as small, dark, discrete spots or water-soaked, sunken lesions on the leaves, stems, or fruits of a wide range of cruciferous plants, including the model plant Arabidopsis thaliana (Narusaka et al., 2004; O'Connell et al., 2004; Birker et al., 2009; Ushimaru et al., 2010). 
C. higginsianum has emerged as an attractive model for studying both fungal pathogenicity and plant immune responses due to the availability of genomic and transcriptomic databases (O'Connell et al., 2012; Gan et al., 2013), and the ease of genetic manipulation of both the host plant and the pathogen (O'Connell et al., 2004; Zhang et al., 2006; Huser et al., 2009; Narusaka et al., 2009).

By recognizing host physical and chemical cues, C. higginsianum conidia differentiate melanized appressorium, an infection structure, at the tips of conidial germ tubes. Appressorium formation is required for successful infection since the fungus penetrates the cuticle and plant cell wall by utilization of enormous turgor pressure in melanized appressoria for further invasive growth (O'Connell et al., 2012). Thus, inhibition of melanized appressorium formation will facilitate the efficient control of anthracnose disease.

The infection-related morphogenesis and invasive growth of several appressorium-forming pathogens are regulated by many signal transduction pathways, especially the mitogenactivated protein kinase (MAPK) pathway (Xu and Hamer, 1996; Lev et al., 1999; Takano et al., 2000; Kojima et al., 2002; Bruno et al., 2004). To date, the MAPK cascades and MAPK signaling pathways are known to be involved in many major cell processes in fungi, such as stress responses, vegetative growth, pathogenicity, secondary metabolism, and cell wall integrity (Zhao et al., 2007; Turrà et al., 2014; Qi et al., 2015). CoMEKK1, a homolog of MAPKKK STE11, the up-stream regulator of Fus3/Kss1-related MAPK pathway, is essential for appressorium development and pathogenicity in C. orbiculare (Sakaguchi et al., 2010). Moreover, the CoIral in C. orbiculare is also involved in infection-related conidial germination and appressorium formation by proper regulation of Fus3/Kss1-related MAPK signaling pathways through CoRas2 on the up-stream (Harata and Kubo, 2014). In Magnaporthe oryzae, phosphodiesterase MoPdeH interacts with MoMck1, and functions upstream of the MoMck1-MoMkk1-MoMps1 MAPK pathway to regulate cell wall integrity (Yin et al., 2016). M. oryzae TRX2 interacts with Mst7, thus regulating the activation of Pmk1 MAPK via the Mst11-Mst7-Pmk1 MAPK pathway. Deletion of the TRX2 gene caused pleiotropic defects in conidiation, growth, responses to stresses, and plant infection progression (Zhang et al., 2016). By phosphorylation on MAPK Fmk1, Fusarium oxysporum Fbp1 regulates virulence, cell wall integrity, and invasive growth via the Fmk1 signal pathway (Miguel-Rojas and Hera, 2016). MAPKs related to the yeast Slt2, such as SLT2-type MAPK protein PsMPK1, and PsMPK7 from Phytophthora sojae are also important for hyphal growth, cell wall integrity, stress tolerance, ROS detoxification, and pathogenicity (Li et al., 2014; Gao et al., 2015). Mutation of three MAPK genes FoSlt2, FoMkk2, and FoBck1 respectively led to attenuated virulence and slower growth rate in F. oxysporum (Ding et al., 2015). The MAPK AaSLT2 in Alternaria alternate regulates conidiation, virulence, and melanin production (Yago et al., 2011). Therefore, these findings suggest significant roles for MAPK signaling pathways in multiple physiological processes of different microorganisms; inhibition on the MAPK signaling pathway of pathogens will disturb infection progresses and facilitate the efficient control of crop disease.
Although many studies have examined MAPK signaling pathways in other fungi, functional analysis in C. higginsianum is still required to understand the intricate roles in the A. thalianaC. higginsianum interaction. To date, compared with other fungi, the specific roles of MAPK for infection-related morphogenesis remain largely unknown in $C$. higginsianum. Because the MAPK pathway contributes to multiple physiological processes of fungal pathogens (Zhang et al., 2016), characterization of C. higginsianum MAPK will help illuminate the mechanism of the cruciferous crops-C. higginsianum interaction and facilitate the efficient control of anthracnose disease. For characterizing the MAPK involved in appressorium formation and pathogenicity ability of $C$. higginsianum, we here investigated the functions of ChMK1 (CH063_08490), an ortholog of PMK1 involved in appressorium differentiation and plant infection in M. oryzae (Bruno et al., 2004). Besides attenuated growth rate, reduced conidiation and albinistic colony, our results firstly indicated that targeted disruption of Fus3/Kss1-related MAPK gene ChMK1 leads to hypersensitivity to cell wall inhibitors. Moreover, the ChMK1 gene disruption mutant also failed to form appressorium and lost its pathogenicity. Here, we have reported the roles of ChMK1 in cell wall integrity, appressorium differentiation, and pathogenicity in C. higginsianum, and demonstrated that the MAPK signaling pathways play essential roles in this fungus.

\section{MATERIALS AND METHODS}

\section{Fungal Strains, Plants, and Culture Condition}

The wild-type C. higginsianum IMI349061 (CH-1) was cultured on potato dextrose agar (PDA) at $25^{\circ} \mathrm{C}$ and stored in PDA slants at $4^{\circ} \mathrm{C}$ for further use. A. thaliana wild-type Col-0 plants were used in this study. Plants were grown in growth chambers at day and night temperatures of $20 \pm 2^{\circ} \mathrm{C}$, with $12 \mathrm{~h}$ of light and $12 \mathrm{~h}$ of darkness. Escherichia coli strain $\mathrm{DH} 5 \alpha$ was used to propagate all plasmids and Agrobacterium tumefaciems strain EHA105 was used for fungal transformation.

\section{Bioinformatics Data and Programs Used in this Study}

The publicly available genomic sequence database of C. higginsianum (http://genome.jgi.doe.gov/Colhi1/Colhi1. home.html) was used to characterize the CH063_08490 gene. NCBI (http://www.ncbi.nlm.nih.gov/) and UniProt (http://www. uniprot.org/blast/) were used for Blastp analysis. The Clustal $X$ program was used for amino acid alignments. MEGA program was used to produce the phylogenetic tree with unrooted neighbor-joining method. The secondary structure prediction was completed with Jnetpred program.

\section{ChMK1 Gene Replacement and Complementary}

For characterizing the ChMK1 gene, a ChMK1 replacement vector, pChMK1-3300, and a complementation vector, pChMK1Com, were constructed. The replacement vector was constructed 
using the homologous recombination strategy. A 0.9-kb fragment upstream of the ChMK1 ORF in the C. higginsianum genome was amplified with primers Rep-up F and Rep-up R (Table 1) and cloned into the Hind III and Sal I sites on pMD18-hph, and the resulting construct was named pMD2- $h p h$. Then a 1.0-kb fragment downstream of ChMK1 ORF was amplified with primers Rep-down F and Rep-down R (Table 1) and cloned between the Xba I and Kpn I sites in pMD2-hph, and the resulting construct was the $C h M K 1$ gene replacement vector, pChMK1-3300 (Figure S1), which had the selective marker $h p h$ gene flanked by the ChMK1 ORF flanking sequences (Figure 2A).

The complementation vector was constructed that ChMK1 cDNA was amplified by RT-PCR with primers Com F and Com $\mathrm{R}$ (Table 1) and cloned into the same sites of pCIT vector, which contained the constitutive $\mathrm{PtrpC}$ promoter and terminator. Finally, the cDNA of ChMK1 was digested with Apa I and cloned into pNeoP3300, resulting in ChMK1 complementation vector, pChMK1-Com.

Agrobacterium-mediated transformation was performed as previously described (Liu et al., 2013) with some modification that plasmid-containing A. tumefaciems cultures (0.6 OD unit at $600 \mathrm{~nm}$ ) were mixed 1:1 with $C$. higginsianum conidial suspension $\left(10^{6}\right.$ spores $\left./ \mathrm{ml}\right)$ in induction broth supplemented with $400 \mu \mathrm{M}$ acetosyringone and cultured for $6 \mathrm{~h}$ at $25^{\circ} \mathrm{C}$ $200 \mathrm{rpm}$, and then cultured on a cellophane membrane laid on co-induction medium supplemented with $400 \mu \mathrm{M}$ acetosyringone at $22^{\circ} \mathrm{C}$ for $48 \mathrm{~h}$. The cellophane membrane were removed to new plates and overlaid with $15 \mathrm{ml}$ PDA containing $500 \mu \mathrm{g} / \mathrm{ml}$ of cephalosporin and $50 \mu \mathrm{g} / \mathrm{ml}$ of hygromycin. After incubation at $25^{\circ} \mathrm{C}$ for $72 \mathrm{~h}$, transformants were transferred to

TABLE 1 | Primers used for vector construction and PCR.

\begin{tabular}{|c|c|}
\hline \multicolumn{2}{|c|}{ Primers used for vector construction and PCR } \\
\hline \multirow{9}{*}{$\begin{array}{l}\text { ChMK1 } \\
\text { replacement } \\
\text { vector for } \\
\text { upstream } \\
\text { ChMK1 } \\
\text { replacement } \\
\text { vector for } \\
\text { downstream } \\
\text { ChMK1 } \\
\text { complementary } \\
\text { vector } \\
\text { ChMK1 for } \\
\text { RT-PCR and } \\
\text { qRT-PCR } \\
\text { PKS1 for qRT-PCR }\end{array}$} & Rep-up F: 5' AAGCTTCCAAAACTTATCGGGGGC 3' \\
\hline & Rep-up R: 5' GTCGACATTGTTGGCGATGTGCG 3' \\
\hline & Rep-down F: 5' TCTAGAGCCCTCAAACACCCTTACC $3^{\prime}$ \\
\hline & Rep-down R: 5' GGTACCGGGCAACGACGACACAAA 3' \\
\hline & Com F: 5' CCCGGGATGTCGCGCGCGAACCCCCCC 3' \\
\hline & Com R: $5^{\prime}$ CTGCAGTCACCGCATGATCTCCTGGTAGATC 3 \\
\hline & RT F: 5' CAAGACCTATCCGACGACCACT 3' \\
\hline & RT R: 5' CAAGACCTATCCGACGACCACT 3' \\
\hline & PKS1 F: 5' AACTGTCCACCACATCCATTCACGC 3' \\
\hline & PKS1 R: 5' AGAGGGTAGAAGGGCACAGAGGAGC 3' \\
\hline \multirow[t]{2}{*}{ THR1 for qRT-PCR } & THR1 F: 5' GTCGCCCGCGAGGCCTACAAGAACC 3' \\
\hline & THR1 R: 5' ACCAAAGTCGATGGCCATGCAGCGG 3' \\
\hline \multirow{2}{*}{$\begin{array}{l}\text { SCD1 for } \\
\text { qRT-PCR }\end{array}$} & SCD1 F: 5' CTGGGACCGCCTCCGCAAGTGCATT 3' \\
\hline & SCD1 R: 5' GAGACCTTCTCGTAGCGGGTGCCGC 3' \\
\hline$\beta$-tubulin for & $\beta$-tubulin F: 5' AGAAAGCCTTGCGACGGAACA 3' \\
\hline & $\beta$-tubulin R: 5' CCTCCAGGGTTTCCAGATTA $3^{\prime}$ \\
\hline
\end{tabular}

PDA plates containing $50 \mu \mathrm{g} / \mathrm{ml}$ of hygromycin for a second round of selection. Transformants were confirmed primarily by RT-PCR with primers RT F and RT R (Table 1) and further confirmed by Southern blot. The C. higginsianum $\beta$-tubulin gene (CH063_04743) (Table 1) was used to normalize the RNA sample for each RT-PCR.

\section{DNA Manipulation and Southern Blot Analysis}

The genomic DNA of C. higginsianum wild-type strain and other derivative mutants was extracted according to the procedure (Sambrook and Russell, 2001).

Southern blot analysis was performed following the method described (Liu et al., 2013). For each sample, 15-20 $\mu$ g genomic DNA was digested with Hind III, size-fractionated through a $0.8 \%$ agarose gel and mounted on positively charged nylon membrane. The nylon membrane was then hybridized with a probe amplified by primers RT-F and RT-R (Table 1) and labeled with digoxigenin (DIG)-dUTP using the PCR DIG Probe Synthesis Kit (Roche, Mannheim, Germany) in accordance with the manufacturer's instructions.

\section{RNA Manipulation and qRT-PCR}

Total RNA of fungal strains was isolated with TriZOL reagent (Invitrogen, Carlsbad, USA) according to manufacturer's instructions and stored at $-80^{\circ} \mathrm{C}$ for further study. The total RNA samples were treated with DNase I (RNase Free) (Takara, Dalian, China) at $37^{\circ} \mathrm{C}$ for $0.5 \mathrm{~h}$ and used to generate the first strand cDNA with RevertAid ${ }^{\mathrm{TM}}$ First Strand cDNA Synthesis Kit (Fermentas, St. Leon-Rot, Germany) according to manufacturer's instructions. The first strand cDNA was stored at $-20^{\circ} \mathrm{C}$ for further study.

Gene expression was analyzed by qRT-PCR using a BioRad CFX96 (Bio-Rad, USA) and SYBR Green PCR mix (BioRad, USA), according to the manufacturer's instructions. The C. higginsianum $\beta$-tubulin gene (CH063_04743) was used to normalize the RNA sample for each qRT-PCR. For each gene, qRT-PCR assays were repeated at least twice, with each repetition having three replicates.

Primer pairs for qRT-PCR detections were designed across or flanking an intron and listed in Table $\mathbf{1 .}$

\section{Characterization of ChMK1 Deletion Transformant and Wild-Type Strain}

The growth rates were assayed that ChMK1 deletion transformant and the wild-type strain were firstly cultivated on PDA for 7 days, then the mycelial agar discs were taken from the active colony edge and inoculated on the center of the PDA petri dish at $25^{\circ} \mathrm{C}$ before hyphal growth was examined. The colony morphology and conidiation of these strains were examined after being grown on PDA plate for 15 days at $25^{\circ} \mathrm{C}$.

The virulence was assayed that $C$. higginsianum strains were cultured on PDA at $25^{\circ} \mathrm{C}$ for 5 days, and the conidia were collected and washed with sterile distilled water twice. The conidial suspension $\left(10^{6}\right.$ conidia/ml $)$ were spotted with $6 \mu \mathrm{l}$ droplets on the leaf surface of 4 -weeks-old Arabidopsis. 
Inoculated leaves were incubated in darkness at $25^{\circ} \mathrm{C}$, and the symptoms were observed at 6 days post-inoculation (dpi).

Conidial germination and appressorial formation were observed that $10 \mu \mathrm{l}$ conidial suspension $\left(10^{6}\right.$ conidia $\left./ \mathrm{ml}\right)$ was spotted on plastic coverslips and incubated at $25^{\circ} \mathrm{C}$ for $24 \mathrm{~h}$. Then, the infection-related morphogenesis was examined by Nikon Eclipse 80i microscope (Nikon, Tokyo, Japan), under bright-field model using $40 \times$ fold magnification.

\section{Cell Wall Sensitivity Assay}

The sensitivity of wild-type strain and the transformants to cell wall inhibitors were performed that mycelial plugs $(4 \mathrm{~mm}$ in diameter) were respectively inoculated onto PDA containing $0.01 \%$ SDS, $300 \mu \mathrm{g} / \mathrm{ml}$ Calcofluor White (CFW), and $300 \mu \mathrm{g} / \mathrm{ml}$ Congo Red (CR) for 7 days as described (Zeng et al., 2012; Luo et al., 2014), and with PDA media as controls. Cell wall sensitivity to the compounds mentioned above was assayed by measuring the colony diameters as previously described (Fujioka et al., 2007; Valiante et al., 2009; Carbo and Perez-Martin, 2010).

\section{Statistical Analysis}

The data assays were analyzed with Origin 7.5 (OriginLab Corporation, Massachusetts, USA) using ANOVA (one-way, $P \leq$ $0.05)$. Results of all graphs represent the mean value \pm SD. Asterisks in the graphs indicate statistical differences, $P \leq 0.05$.

\section{RESULTS}

\section{CH063_08490 is Similar to MAPK Protein}

The SMART MODE (http://smart.embl-heidelberg.de/smart/ change_mode.pl) analysis result indicates that CH063_08490 contains a Serine/Threonine protein kinases catalytic (S_TKc) domain (Figure 1A), which plays a key role in catalysis of protein phosphorylation. The BLAST searches of CH063_08490 for homologous sequences resulted in significant similarity with sequences from $M$. oryzae PMK1 (XP_003712175.1, Evalue: $0.0,98.9 \%$ identity), Cochliobolus heterostrophus CHK1 (AF178977.1, E-value: 0.0, 94\% identity), Botrytis cinerea BMP1 (AF205375.1, E-value: 0.0, 94.6\% identity), F. oxysporum FMK1 (AAG01162.1, E-value: 0.0, 98.3\% identity) and Colletotrichum lagenarium CMK1 (AAD50496.1, E-value: 0.0, 99.4\% identity) that match to the MAPK proteins. Sequence multiple alignment analysis of these homologs revealed significant conservation in length and amino acid composition (Figure 1B). Phylogenetic analysis indicated that $\mathrm{CH} 063$ 08490 is closely related to CMK1 (Figure 1C), a MAPK in C. lagenarium involved in conidiation, appressorium formation, and pathogenicity (Takano et al., 2000).

In summary, the protein coded by $\mathrm{CH} 063 \_08490$ resembles MAPK proteins, thus we named this gene as ChMK1 derived from $\underline{C}$. higginsianum $\underline{M A P} \underline{\text { K. }}$.

\section{Gene Disruption and Complementation of ChMK1}

For function study of ChMK1 gene in C. higginsianum, we generated ChMK1 deletion mutants. Deletion transformants were screened by growing on PDA containing hygromycin and further confirmed by Southern blot and RT-PCR (Figures 2C,D).
TABLE 2 | Comparison of growth rate and conidial production among ChMK1 deletion mutants, complementary strain and wild-type strain.

\begin{tabular}{lcc}
\hline Strains & Growth $^{\text {rate }}{ }^{\mathrm{a}} \mathbf{( \mathbf { m m } / \mathbf { d } )}$ & Condiation $^{\mathrm{b}}\left(\mathbf{\times} \mathbf{1 0 ^ { \mathbf { 6 } } \text { condia/plate } )}\right.$ \\
\hline Wild-type & $5.1 \pm 0.2^{\mathrm{A}}$ & $24.0 \pm 2.0^{\mathrm{A}}$ \\
$\Delta$ ChMK1-1 & $2.8 \pm 0.1^{\mathrm{B}}$ & $6.4 \pm 0.7^{\mathrm{B}}$ \\
$\Delta$ ChMK1-8 & $2.9 \pm 0.1^{\mathrm{B}}$ & $5.7 \pm 0.6^{\mathrm{B}}$ \\
ChMK1-Com & $5.2 \pm 0.2^{\mathrm{A}}$ & $26.5 \pm 2.0^{\mathrm{A}}$ \\
\hline
\end{tabular}

a Growth rate was detected by measuring the colony diameter of cultures incubated at $25^{\circ} \mathrm{C}$ for 7 days. ${ }^{b}$ Conidia produced by 15 -days-old cultures and counted with haematocytometer. Different letters indicated statistically significant differences $(P=0.05)$. Means and standard errors were calculated from three replicates.

Two deletion mutants $\triangle$ ChMK1-1 and $\triangle$ ChMK1-8, which had the marker inserted into regions other than the ChMK1 gene, were selected for further analysis in this study. Furthermore, for complementation of the ChMK1 deletion mutant, the complementary vector pChMK1-Com was transformed into deletion mutant $\triangle \mathrm{ChMK} 1-1$, and the complemented transformants ChMK1-Com, confirmed by RT-PCR was selected for further analysis (Figure 2D).

\section{ChMK1 Deletion Transformant Shows Abnormal Phenotype}

The infection assay of ChMK1 deletion mutant was performed as described above. Conidia suspension of wild-type strain, ChMK1 deletion strain $\triangle \mathrm{ChMK1-1}$ and $C h M K 1$ complementary strain ChMK1-Com were inoculated on Arabidopsis leaves. At 6 dpi, the wild-type and ChMK1-Com strains could cause dark necrotic lesions (Figure 3A), whereas the ChMK1 deletion transformant failed to cause any lesion on the leaves of Arabidopsis after inoculating $\triangle \mathrm{ChMK1-1}$ mutants for 6 days (Figure 3A), which is similar with previous study that the MAPK mutant of C. lagenarium did not develop any lesions, even inoculated on wounded plants (Takano et al., 2000). These results indicate that ChMK1 is essential for the pathogenicity of C. higginsianum on Arabidopsis.

The ChMK1 affects the melanin formation and growth rate of C. higginsianum. Compared with wild-type strain and ChMK1 complementary strain, the ChMK1 deletion transformant showed obvious albino colony (Figure 2B), reduction of conidiation (Table 2), and reduced growth rate on PDA (Table 2). Appressorium formation of the ChMK1 deletion mutants on the hydrophobic surface (plastic coverslips) was investigated by microscopic observation. Conidia of the wildtype strain and ChMK1 complementary strain could formed melanized appressoria on the plastic coverslips after incubation for $24 \mathrm{~h}$, while ChMK1 deletion mutant failed to differentiate into appressoria (Figure 3B). It concluded from these results that ChMK1 regulate appressorium formation, thus to affect the pathogenicity of C. higginsianum.

\section{ChMK1 is Significant for the Maintenance of Cell-Wall Integrity}

Previous studies indicated that MAPK signal pathway contributed to cell wall integrity in multiple fungi (Jeon et al., 2008; Zeng et al., 2012; Ding et al., 2015), in our study, 
A

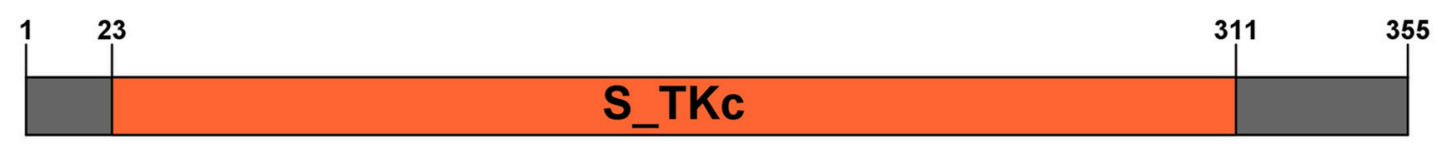

\section{$6.71 e-98$}

\section{0 aa}

B
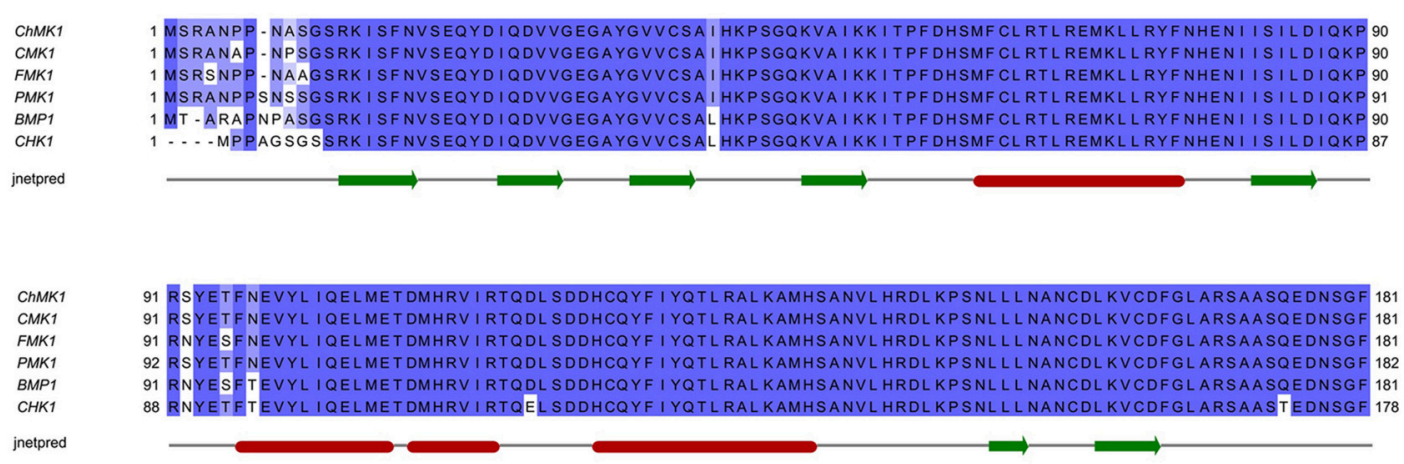

(2)

CHMK1 182 MTEYVATRWYRAPE IML TFKEYTKA I DVWSVGCILAEML SGKPLFPGKDYHHQL TL ILDVLGTPTMEDYYG I KSRRAREY IRSLPFKKKVP 272
CMK1

CMK1 182 MTEYVATRWYRAPE IMLTFKEYTKA I DVWSVGCILAEML SGKPLFPGKDYHHQLTL ILDVLGTPTMEDYYG IKSRRAREYIRSLPFKKKVP 272

FMK1 182 MTEYVATRWYRAPE IMLTFKEYTKA I DVWSVGCILAEML SGKPLFPGKDYHHQLTL IL DVLGTPTMEDYYG IKSRRAREYIRSLPFKKKVP 272

PMK1 183 MTEYVATRWYRAPE IMLTFKEYTKA I DVWSVGCILAEML SGKPLFPGKDYHHQLTL ILDVLGTPTMEDYYG IKSRRAREYIRSLPFKKKVP 273

$\begin{array}{ll}\text { BMP1 } & 182 \text { MTEYVATRWYRAPE IMLTFKEYTKA I DVWSVGCILAEML SGKPLFPGKDYHHQLTL ILDVLGTPTMEDYYGIKSRRAREY IRSLPFKKKVP 272 } \\ \text { CHK1 } & 179 \text { MTEYVATRWYRAPE IMLTFKEYTKA I DVWSVG ILAEML SGKPLFPGKDHHQLTL ILDVLGTPTMEDYYIKSRRAREYIRSLPFKKK IP269 }\end{array}$

jnetpred

C

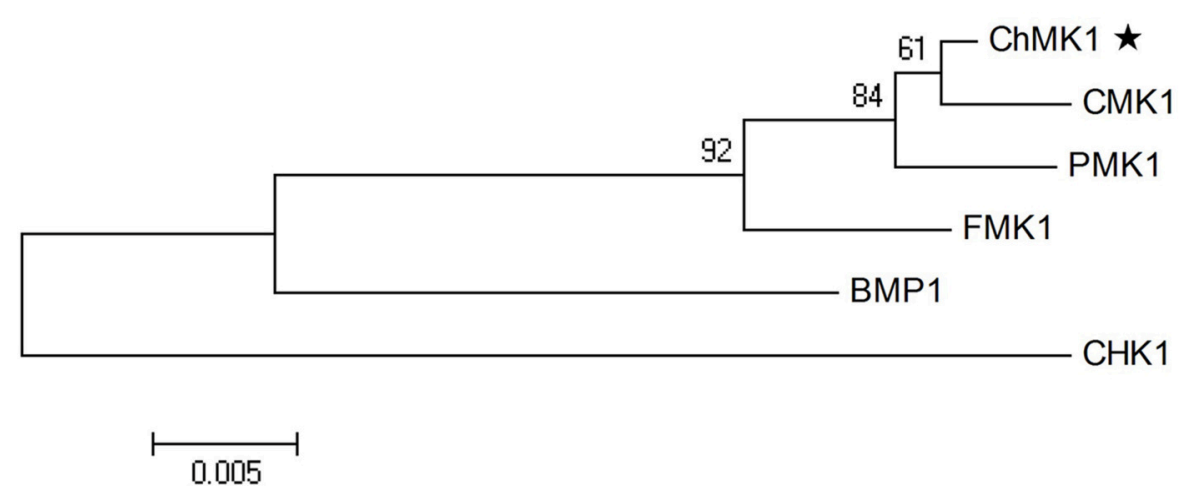

FIGURE 1 | Characterization of the C. higginsianum ChMK1 protein. (A) The domain structure of C. higginsianum ChMK1 as annotated by SMART MODE (http://smart.embl-heidelberg.de/smart/change_mode.pl). (B) Alignment analysis of the amino acid sequences of ChMK1 (CH063_08490) and its homologs from other fungi using Clustal X program. PMK1: XP_003712175.1 (M. oryzae); CHK1: AF178977.1 (C. heterostrophus); BMP1: AF205375.1 (B. cinerea); 


\section{FIGURE 1 | Continued}

FMK1: AAG01162.1 (F. oxysporum); CMK1: AAD50496.1 (C. lagenarium). The conserved kinase activation residues TEY are labeled with asterisks at the top of the alignment. The secondary structure prediction was completed with Jnetpred program. The green arrows indicate $\beta$-strands structure and the red sticks indicate $\alpha$-helix structure. (C) Phylogenetic analysis of ChMK1 of $C$. higginsianum and its homologs from other fungi. The amino acid sequences were analyzed by MEGA version 4 with Unrooted Neighbor-joining algorithm. Bootstrap values were calculated from 1000 bootstrap replicates. Only bootstrap support values $>50 \%$ are shown. The black star indicates ChMK1.

\section{A}

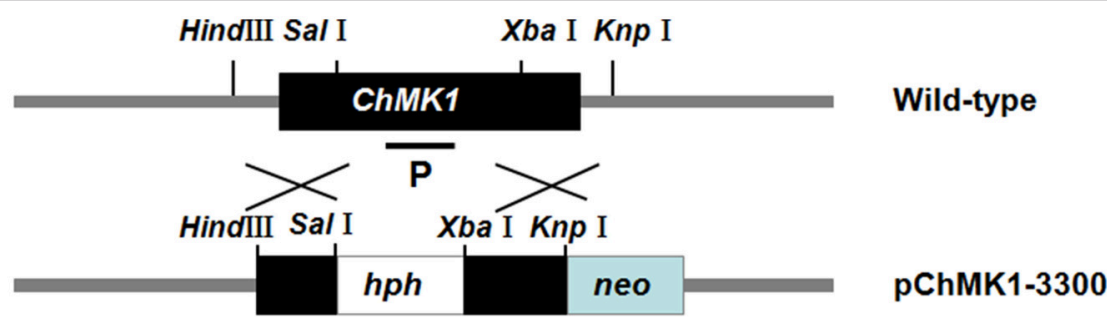

B

$\mathrm{CH}-1$

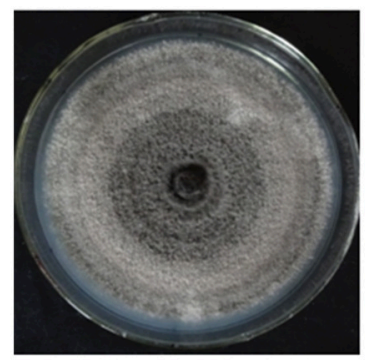

$\triangle$ ChMK1-1

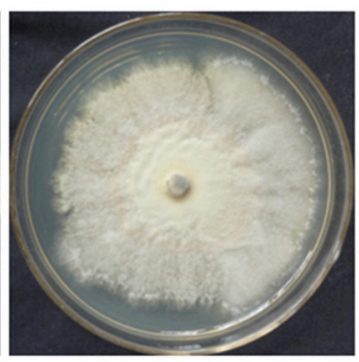

$\triangle$ ChMK1-8

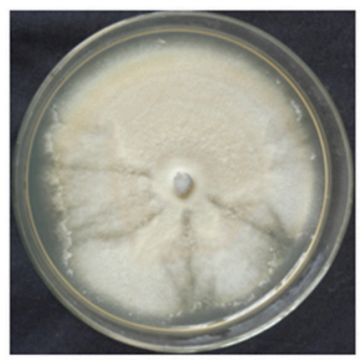

ChMK1-Com

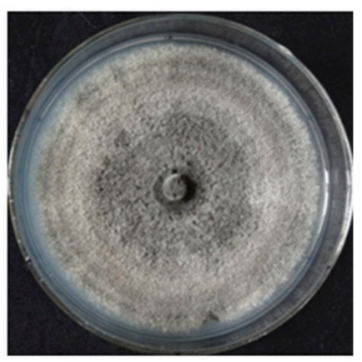

C

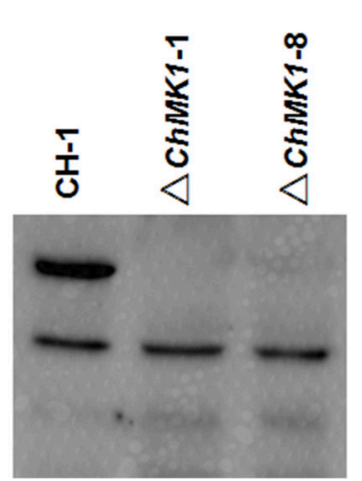

D

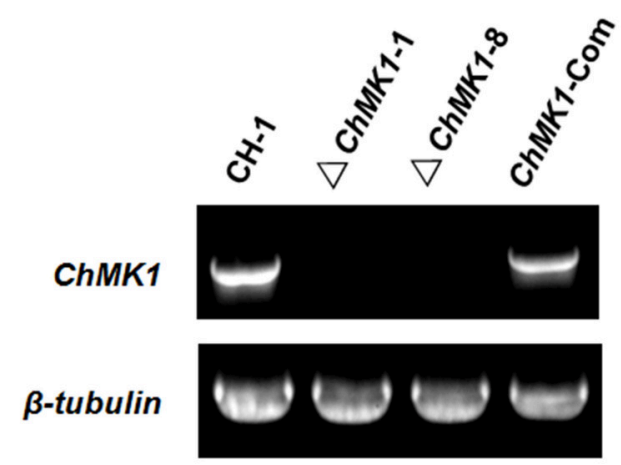

FIGURE 2 | Construction of replacement vectors and confirmation of ChMK1 deletion mutants. (A) Strategic map of the ChMK1 replacement construct pChMK1-3300. Thick arrows indicate the orientations of ChMK1 and hygromycin phosphotransferase (hph) gene. The hph gene cassette was cloned into the corresponding sites of vector pChMK1-3300 to replace the 1108-bp of the ChMK1 ORF. (B) Colony morphologies of CH-1, $\triangle$ ChMK1-1, $\triangle$ ChMK1-8, and

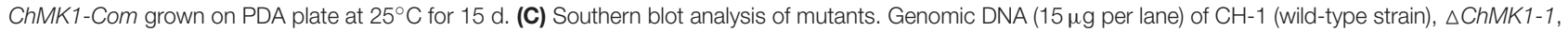
$\triangle C h M K 1-8$, and ChMK1-Com (ChMK1 complementary transformant) were digested with Sacl. The same filter was hybridized with a probe corresponding to the ChMK1 (P). (D) Total RNA samples isolated from mycelia of CH-1, $\triangle$ ChMK1-1, $\triangle$ ChMK1-8, and ChMK1-Com were subjected to RT-PCR using ChMK1 gene-specific primers $4 \mathrm{~F}$ and $4 \mathrm{R}$ (Table 1). The RT-PCR product is a $560 \mathrm{bp}$ fragment in $\mathrm{CH}-1$ and ChMK1-Com as predicted, but is missing in the deletion mutants $\triangle C h M K 1-1, \triangle C h M K 1-8$.

the sensitivity of wild-type strain, ChMK1 complementary strain and ChMK1 deletion transformant to three cell wall inhibitors was also tested. The results indicated that ChMK1 deletion transformant was more sensitive to SDS, Calcofluor
White (CFW) and Congo Red (CR) than wild-type strain and the complementary transformant (Figure 4A). Data showed that the inhibition of the growth rate of ChMK1 deletion transformant were higher than that of wild-type strain and 
A

\section{$0.5 \mathrm{~cm}$}

$\mathrm{CH}-1$

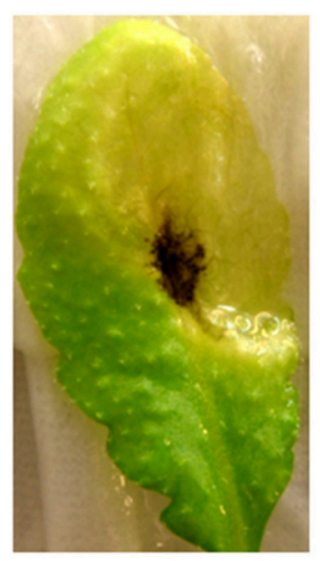

$\triangle \mathrm{ChMK1-1}$

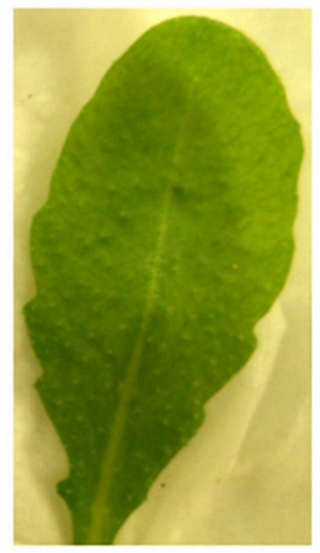

\section{ChMK1-Com}

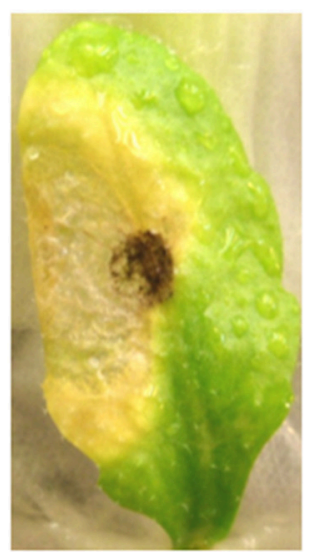

B

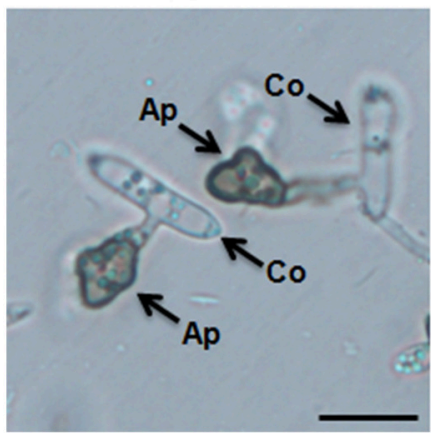

$\triangle$ ChMK1-1

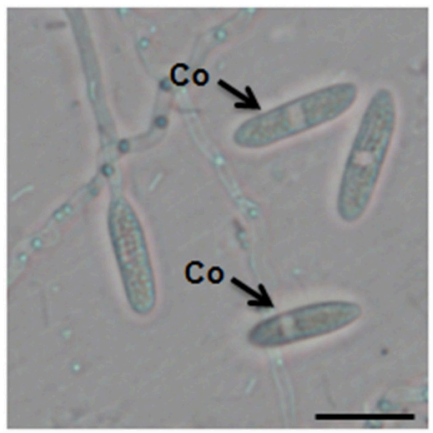

ChMK1-Com

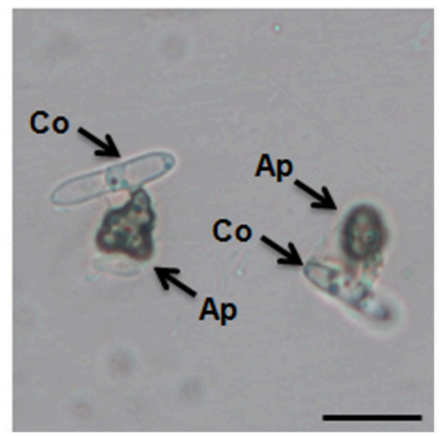

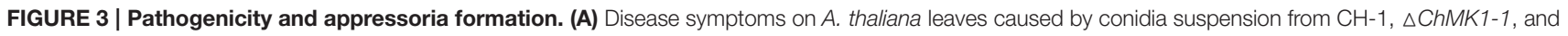
ChMK1-Com. Typical leaves were photographed 6 days after inoculation. Bar $=0.5 \mathrm{~cm}$. (B) The development of appressoria on plastic microscopic coverslips at $25^{\circ} \mathrm{C}$ for $24 \mathrm{~h}$ by using Nikon Eclipse 80i microscope (Nikon, Tokyo, Japan), under bright-field model with $40 \times$ fold magnification. Ap, appressoria; Co, conidia. Bars $=10 \mu \mathrm{m}$.

ChMK1 complementary strain when cultured on PDA amended with those cell wall inhibitors respectively (Figure 4B).

\section{ChMK1 Regulates the Expression of Melanin Biosynthesis-Associated Genes}

Previous studies revealed a crucial role of MAPK signal pathway in melanin biosynthesis in several other fungi (Takano et al., 2000; Yago et al., 2011; Zeng et al., 2012). In our study, the C. higginsianum ChMK1 deletion mutant was also unable to form melanized colony as wild-type, we speculated that the biosynthesis of dihydroxynaphthalene (DHN) melanin was interrupted. In order to verify this assumption, the expression level of three major melanin biosynthetic-associated genes, $\beta$ ketoacyl synthase (PKS1, CH063_03518), trihydroxynaphthalene reductase (THR1, CH063_06688), and scytalone dehydratase (SCD1, CH063_08047), were compared between ChMK1 deletion mutant, complementary strain and wild-type strain using qRTPCR. The results indicated that the expression level of these three genes in ChMK1 deletion mutant mycelia was significantly reduced compared with that of the complementary and wild-type strains (Figure 5). Similar results were also obtained in other studies that the expression level of melanin biosyntheticassociated genes were decreased in MAPK mutants (Takano et al., 2000; Wei et al., 2016).

\section{DISCUSSION}

In this study, we characterized the Fus3/Kss1-related MAPK ChMK1 to assess the roles of MAPK pathways in the fungal pathogenesis of C. higginsianum. Gene deletion and complementary analysis of ChMK1 demonstrated that this gene is essential for appressorium formation, pathogenicity, 
A
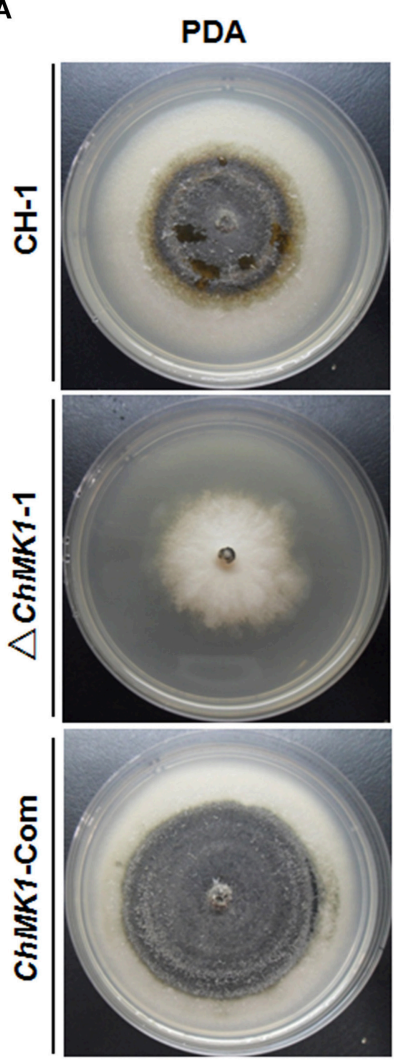

\section{$0.01 \%$ SDS}
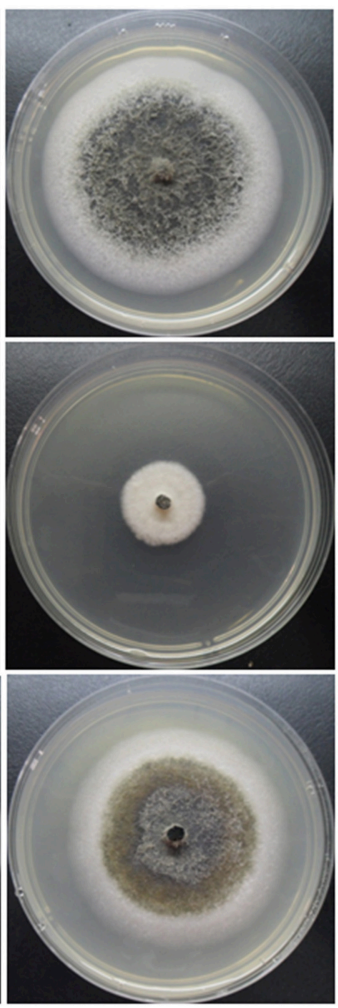

$300 \mu \mathrm{g} / \mathrm{ml} \mathrm{CR}$
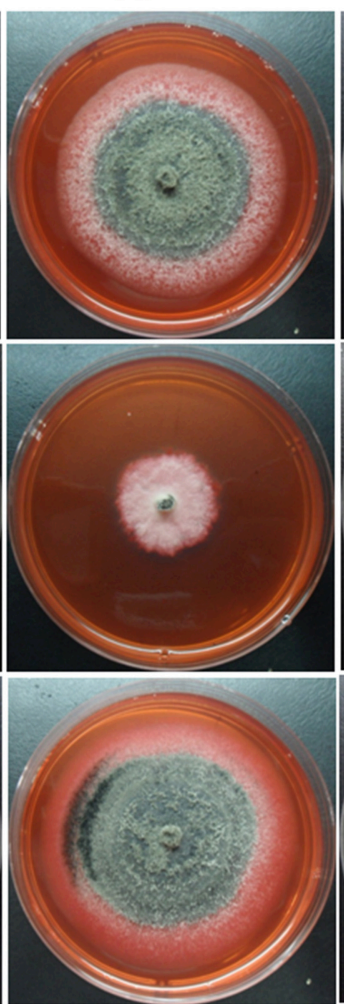

$300 \mu \mathrm{g} / \mathrm{ml} \mathrm{CFW}$
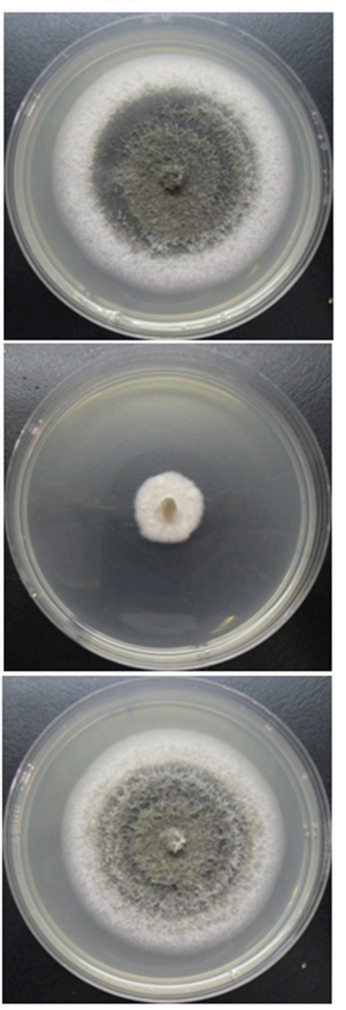

B
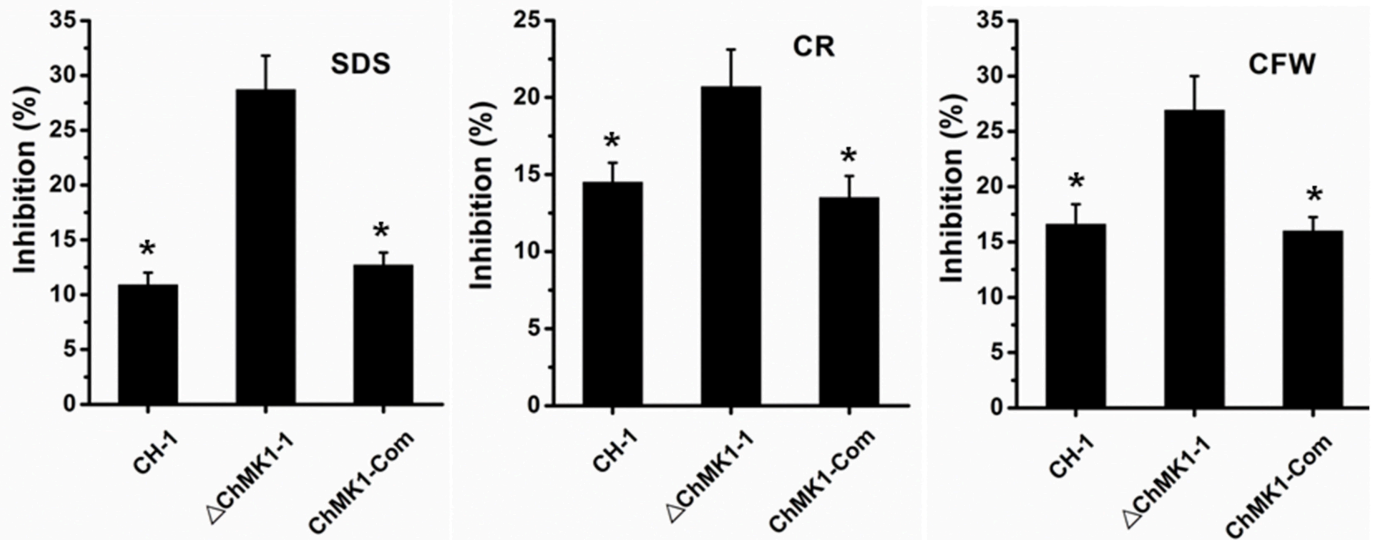

FIGURE 4 | Cell wall integrity assays of $\mathbf{C}$. higginsianum to cell wall inhibitor. (A) $\mathrm{CH}-1, \triangle \mathrm{ChMK1-1}$, and ChMK1-Com treated with indicated cell wall inhibitor in PDA. Images were taken after 7 days of incubation on PDA with $0.01 \%$ SDS, $300 \mu \mathrm{g} / \mathrm{ml}$ Calcofluor White (CFW), and $300 \mu \mathrm{g} / \mathrm{ml}$ Congo Red (CR). (B) Inhibition of the radiated growth of $\mathrm{CH}-1, \triangle \mathrm{ChMK1-1}$, and ChMK1-Com on the PDA with cell wall inhibitor. Means and standard errors were calculated from three replicates. Asterisks indicate statistical differences from the $\triangle C h M K 1-1(P<0.05)$.

conidiation production, growth rate, maintenance of cell-wall integrity, and melanin formation in C. higginsianum.

In F. oxysporum, C. lagenarium, M. oryzae, and Pyrenophora teres, deletion mutants of Fus3/Kss1-related MAPK genes showed normal growth rates (Xu and Hamer, 1996; Takano et al.,
2000; Di Pietro et al., 2001; Ruiz-Roldan et al., 2001; Luque et al., 2016), whereas the opposite was observed in B. cinerea and Ustilago maydis (Mayorga and Gold, 1999; Zheng et al., 2000). In our study, the growth rate of ChMK1 deletion mutants was significantly decreased compared to wild type strain (Table 2), 

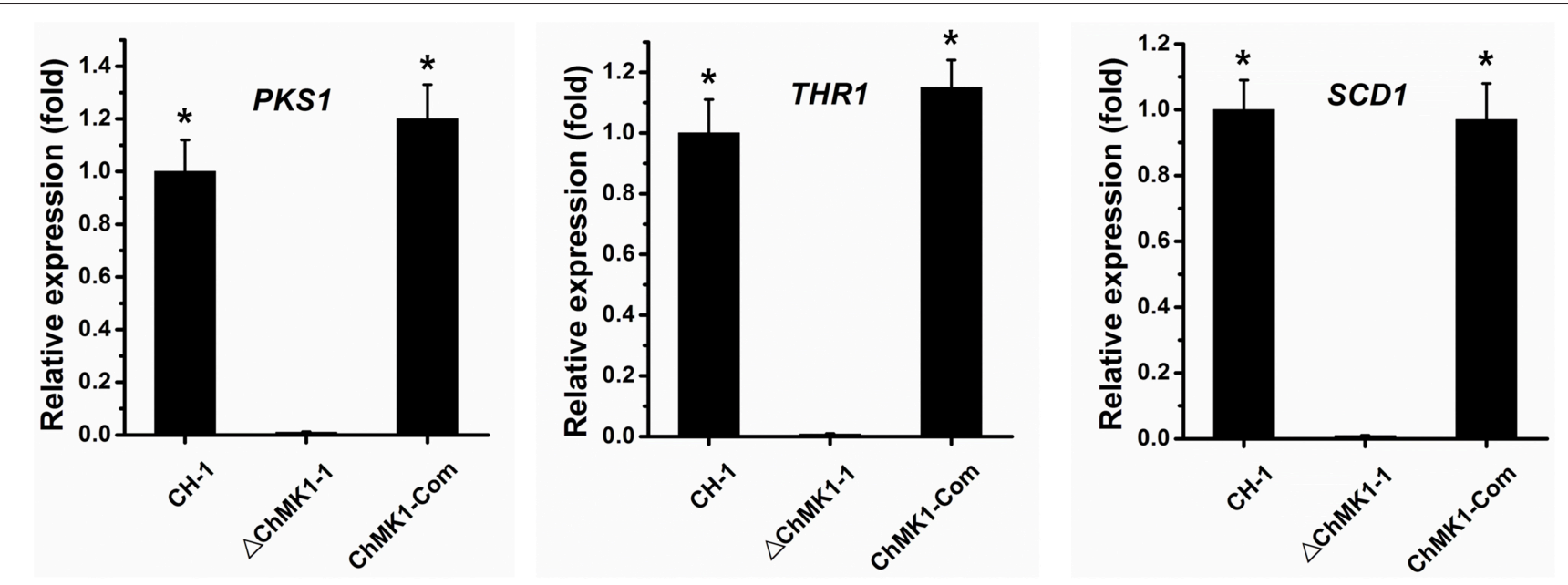

FIGURE 5 | The relative expression of PKS1, THR1, and SCD1 in CH-1, $\triangle$ ChMK1-1, and ChMK1-Com cultured on PDA for 4 d. The relative expression of target genes in $\mathrm{CH}-1$ was set as level 1. Expression level of $\beta$-tubulin gene was used to normalize different samples. Bars represent means and standard deviations (three replications). Asterisks indicate statistical differences from the $\triangle$ ChMK1-1 $(P<0.05)$.

supporting the diverse functions of Fus3/Kss1-related MAPKs in different plant fungal pathogens. Furthermore, the Fus3/Kss1related MAPK signal pathway from several plant pathogen fungi plays significant roles in conidiation, appressorium formation, and fungal pathogenicity (Mayorga and Gold, 1999; Ruiz-Roldan et al., 2001; Zhao et al., 2007; Miguel-Rojas and Hera, 2016; Zhang et al., 2016). In this study, the albinistic ChMK1 deletion mutant also showed a significant reduction in conidiation production (Table 2) and defects in appressorium formation, thus losing pathogenicity (Figure 3). These results indicate the conserved roles of Fus3/Kss1-related MAPKs in phytopathogenic fungi.

SLT2-type MAPKs, another type of MAPKs, are involved in cell wall integrity and stress tolerance in multiple fungi and Phytophthora species (Gao et al., 2015). In Coniothyrium minitans, CmSlt2 was involved in conidiation, cell wall integrity, and mycoparasitism, targeted disruption of CmSlt2 led to hypersensitivity to cell wall-degrading enzymes and cell wall inhibitors caffeine, CFW and CR (Zeng et al., 2012). In F. oxysporum, disruption of the MAPK FoSlt2 gene resulted in increased sensitivity to $\mathrm{H}_{2} \mathrm{O}_{2}$ and cell wall inhibitors CR and CFW (Ding et al., 2015). In M. oryzae, MoMck1-MoMkk1-MoMps1 MAPK pathway contributed to regulate cell wall integrity (Yin et al., 2016). Moreover, silencing of PsMPK1 in P. sojae caused increased hypersensitivity to cell wall-degrading enzymes cellulase and lysing enzyme (Li et al., 2014). Similar results were obtained in A. alternata, since the AaSLT2 mutants also displayed hypersensitivity to cell wall-degrading enzymes, CFW and CR (Yago et al., 2011). Nevertheless, until recently, there has been little experimental evidence for the contribution of Fus3/Kss1-related MAPKs to cell wall integrity in fungi. In this study, our results firstly demonstrated that the Fus3/Kss1-related MAPK ChMK1 from C. higginsianum also plays a significant role in cell wall integrity, and deletion of ChMK1 cause increased hypersensitivity to cell wall inhibitors (Figure 4).
Furthermore, the deletion mutants of ChMK1 showed obviously albino colony (Figure 2B). Since DHN melanin is required for melanization, which is essential for appressorial functions and virulence in Colletotrichum species (Rasmussen and Hanau, 1989; Lin et al., 2012), we speculated that the biosynthesis of DHN melanin was interrupted in the deletion mutant of ChMK1. The qRT-PCR results in this study demonstrated that the expression levels of PKS1, THR1, and SCD1, the major DHN melanin biosynthetic-associated genes (Takano et al., 1997), decreased significantly in ChMK1 deletion mutant when compared to wild-type strain (Figure 5), which was similar with other studies that the expression level of melanin biosynthetic-associated genes decreased in MAPK mutants (Takano et al., 2000; Wei et al., 2016), indicating that ChMK1 is involved in the biosynthesis of DHN melanin by regulating the expression of DHN melanin biosynthetic-associated genes.

Most fungal pathogens contain three MAPKs that are orthologs of the S. cerevisiae Fus3/Kss1, Slt2, and Hog1 MAPK. Recent study demonstrated that Fus3/Kss1, Slt2, and Hog1 MAPKs have distinct and complementary roles, and the positive and negative crosstalk between three MAPK pathways regulates stress adaptation, development and virulence in $F$. oxysporum (Luque et al., 2016). In M. oryzae, it was reported that the feedback between the cAMP and MAPK signaling pathways regulate appressorium morphogenesis and plant infection (Zhou et al., 2012). In C. lagenarium, Cmk1 MAPK cooperated with cAMP-PKA signaling pathway to regulate germination, appressorium formation and infectious growth, and mutation of these genes led to similar defects in germination, appressorium formation, and infectious growth (Takano et al., 2000; Yamauchi et al., 2004). In B. cinerea, Nox-, calcium-, and MAPKsignaling cascades incorporated with RasGAP scaffold protein BcIqg1 to regulate several developmental processes and virulence (Marschall and Tudzynski, 2016). Similar results were also 
obtained in mycoparasite C. minitans that MAPK cascade and Nox complex signal pathway are cross-linked and essential for pathogenicity, melanin synthesis and conidiation (Wei et al., 2016). In our study, deletion of ChMK1 resulted in decreased growth rate, defects in virulence, and appressorial formation, hypersensitivity to cell wall inhibitors, reduced conidiation, and albinistic colony. These phenotype of ChMK1 mutant are similar with that of the mutants of other signaling pathway in other fungi (Zhou et al., 2012; Luque et al., 2016; Marschall and Tudzynski, 2016; Wei et al., 2016). Thus, it was speculated that C. higginsianum MAPK cascade also cross-linked with other signal pathways possibly to regulate multiple physiological processes in C. higginsianum.

Briefly, we have analyzed the functions of ChMK1 in appressorium formation, pathogenicity, growth rate, conidiation and melanin production in C. higginsianum. Moreover, we also firstly reported that the Fus3/Kss1-related MAPK is involved in the maintenance of cell-wall integrity. The results described above will enhance our understanding of the mechanism underlying $A$. thaliana-C. higginsianum interaction and will facilitate the efficient control of cruciferous crops anthracnose disease.

\section{CONCLUSION}

The Fus3/Kss1-related MAPK ChMK1 was experimentally confirmed to be essential to appressorium formation, pathogenicity, growth rate, conidiation production, and

\section{REFERENCES}

Birker, D., Heidrich, K., Takahara, H., Narusaka, M., Deslandes, L., Narusaka, Y., et al. (2009). A locus conferring resistance to Colletotrichum higginsianum is shared by four geographically distinct Arabidopsis accessions. Plant J. 60, 602-613. doi: 10.1111/j.1365-313X.2009.03984.x

Bruno, K. S., Tenjo, F., Li, L., Hamer, J. E., and Xu, J. R. (2004). Cellular localization and role of kinase activity of PMK1 in Magnaporthe grisea. Eukaryot. Cell 3, 1525-1532. doi: 10.1128/EC.3.6.1525-1532.2004

Carbo, N., and Perez-Martin, J. (2010). Activation of the cell wall integrity pathway promotes escape from G2 in the fungus Ustilago maydis. PLoS Genet. 6:e1001009. doi: 10.1371/journal.pgen.1001009

Ding, Z., Li, M., Sun, F., Xi, P., Sun, L., Zhang, L., et al. (2015). Mitogen-activated protein kinases are associated with the regulation of physiological traits and virulence in Fusarium oxysporum f. sp. cubense. PLoS ONE 10:e0122634. doi: 10.1371/journal.pone.0122634

Di Pietro, A., García-MacEira, F. I., Méglecz, E., and Roncero, M. I. (2001). A MAP kinase of the vascular wilt fungus Fusarium oxysporum is essential for root penetration and pathogenesis. Mol. Microbiol. 39, 1140-1152. doi: 10.1111/j.1365-2958.2001.02307.x

Fujioka, T., Mizutani, O., Furukawa, K., Sato, N., Yoshimi, A., Yamagata, Y., et al. (2007). MpkA-dependent and -independent cell wall integrity signaling in Aspergillus nidulans. Eukaryot. Cell 6, 1497-1510. doi: 10.1128/EC.00281-06

Gan, P., Ikeda, K., Irieda, H., Narusaka, M., O'Connell, R. J., Narusaka, Y., et al. (2013). Comparative genomic and transcriptomic analyses reveal the hemibiotrophic stage shift of Colletotrichum fungi. New Phytol. 197, 1236-1249. doi: $10.1111 /$ nph. 12085

Gao, J., Cao, M., Ye, W., Li, H., Kong, L., Zheng, X., et al. (2015). PsMPK7, a stressassociated mitogen-activated protein kinase (MAPK) in Phytophthora sojae, is required for stress tolerance, reactive oxygenated species detoxification, cyst germination, sexual reproduction and infection of soybean. Mol. Plant Pathol. 16, 61-70. doi: $10.1111 / \mathrm{mpp} .12163$ melanin formation in C. higginsianum. Furthermore, our results also firstly showed the involvement of Fus3/Kss1-related MAPK in cell wall integrity, indicating that ChMK1 plays diverse and essential roles in this fungus.

\section{AUTHOR CONTRIBUTIONS}

Conceived and designed the experiments: WW, WZ. Performed the experiments: WW, WZ. Analyzed the experiment data: WW, YX, WZ, NW, GY, FP. Contributed reagents/materials/analysis tools: WW, WZ. Wrote the paper: WW, WZ. All authors have read and approve the final manuscript.

\section{ACKNOWLEDGMENTS}

The research was financially supported by the National Natural Science Foundation of China (31501587), Scientific Research Foundation Granted From Jianghan University, and Scientific Research Foundation Granted From Wuhan Polytechnic University. We thank reviewers for their kind suggestions.

\section{SUPPLEMENTARY MATERIAL}

The Supplementary Material for this article can be found online at: http://journal.frontiersin.org/article/10.3389/fmicb. 2016.01212

Figure $\mathrm{S} 1$ | The vector map of pChMK1-3300.

Harata, K., and Kubo, Y. (2014). Ras GTPase activating protein CoIra1 is involved in infection-related morphogenesis by regulating cAMP and MAPK signaling pathways through CoRas2 in Colletotrichum orbiculare. PLoS ONE 9:e109045. doi: 10.1371/journal.pone.0109045

Huser, A., Takahara, H., Schmalenbach, W., and O'Connell, R. (2009). Discovery of pathogenicity genes in the crucifer anthracnose fungus Colletotrichum higginsianum, using random insertional mutagenesis. Mol. Plant Microbe Interact. 22, 143-156. doi: 10.1094/MPMI-22-2-0143

Jeon, J., Goh, J., Yoo, S., Chi, M. H., Choi, J., Rho, H. S., et al. (2008). A putative MAP kinase kinase kinase, MCK1, is required for cell wall integrity and pathogenicity of the rice blast fungus, Magnaporthe oryzae. Mol. Plant Microbe Interact. 21, 525-534. doi: 10.1094/MPMI-21-5-0525

Kojima, K., Kikuchi, T., Takano, Y., Oshiro, E., and Okuno, T. (2002). The mitogen-activated protein kinase gene $M A F 1$ is essential for the early differentiation phase of appressorium formation in Colletotrichum lagenarium. Mol. Plant Microbe Interact. 15, 1268-1276. doi: 10.1094/MPMI.2002.15.12.1268

Lev, S., Sharon, A., Hadar, R., Ma, H., and Horwitz, B. A. (1999). A mitogenactivated protein kinase of the corn leaf pathogen Cochliobolus heterostrophus is involved in conidiation, appressorium formation, and pathogenicity: diverse roles for mitogen-activated protein kinase homologs in foliar pathogens. Proc. Natl. Acad. Sci. U.S.A. 96, 13542-13547. doi: 10.1073/pnas.96.23. 13542

Li, A., Zhang, M., Wang, Y., Li, D., Liu, X., Tao, K., et al. (2014). PsMPK1, an SLT2-type mitogen-activated protein kinase, is required for hyphal growth, zoosporogenesis, cell wall integrity, and pathogenicity in Phytophthora sojae. Fungal Genet. Biol. 65, 14-24. doi: 10.1016/j.fgb.2014. 01.003

Lin, S., Okuda, S., Ikeda, K., Okuno, T., and Takano, Y. (2012). LAC2 encoding a secreted laccase is involved in appressorial melanization and conidial pigmentation in Colletotrichum orbiculare. Mol. Plant Microbe Interact. 25, 1552-1561. doi: 10.1094/MPMI-05-12-0131-R 
Liu, L., Zhao, D., Zheng, L., Hsiang, T., Wei, Y., Fu, Y., et al. (2013). Identification of virulence genes in the crucifer anthracnose fungus Colletotrichum higginsianum by insertional mutagenesis. Microb. Pathog. 64, 6-17. doi: 10.1016/j.micpath.2013.06.001

Luo, Y., Zhang, H., Qi, L., Zhang, S., Zhou, X., Zhang, Y., et al. (2014). FgKin1 kinase localizes to the septal pore and plays a role in hyphal growth, ascospore germination, pathogenesis, and localization of Tub1 beta-tubulins in Fusarium graminearum. New Phytol. 204, 943-954. doi: 10.1111/nph.12953

Luque, D. S., Di Pietro, A., Pérez-Nadales, E., and Turrà, D. (2016). Three Fusarium oxysporum MAPKs have distinct and complementary roles in stress adaptation and cross-kingdom pathogenicity. Mol. Plant Pathol. doi: 10.1111/mpp.12446. [Epub ahead of print].

Marschall, R., and Tudzynski, P. (2016). BcIqg1, a fungal IQGAP homolog, interacts with NADPH oxidase, MAP kinase and Calcium signaling proteins and regulates virulence and development in Botrytis cinerea. Mol. Microbiol. 101, 281-298. doi: 10.1111/mmi.13391

Mayorga, M. E., and Gold, S. E. (1999). A MAP kinase encoded by the $u b c 3$ gene of Ustilago maydis is required for filamentous growth and full virulence. Mol. Microbiol. 34, 485-497. doi: 10.1046/j.1365-2958.1999.01610.x

Miguel-Rojas, C., and Hera, C. (2016). The F-box protein Fbpl functions in the invasive growth and cell wall integrity mitogen-activated protein kinase (MAPK) pathways in Fusarium oxysporum. Mol. Plant Pathol. 17, 55-64. doi: 10.1111/mpp.12259

Narusaka, M., Shirasu, K., Noutoshi, Y., Kubo, Y., Shiraishi, T., Iwabuchi, M., et al. (2009). RRS1 and RPS4 provide a dual Resistance-gene system against fungal and bacterial pathogens. Plant J. 60, 218-226. doi: 10.1111/j.1365313X.2009.03949.x

Narusaka, Y., Narusaka, M., Park, P., Kubo, Y., Hirayama, T., Seki, M., et al. (2004). $\mathrm{RCH} 1$, a locus in Arabidopsis that confers resistance to the hemibiotrophic fungal pathogen Colletotrichum higginsianum. Mol. Plant Microbe Interact. 17, 749-762. doi: 10.1094/MPMI.2004.17.7.749

O’Connell, R., Herbert, C., Sreenivasaprasad, S., Khatib, M., Esquerré-Tugayé, M. -T., and Dumas, B. (2004). A novel Arabidopsis-Colletotrichum pathosystem for the molecular dissection of plant-fungal interactions. Mol. Plant Microbe Interact. 17, 272-282. doi: 10.1094/MPMI.2004.17.3.272

O’Connell, R. J., Thon, M. R., Hacquard, S., Amyotte, S. G., Kleemann, J., Torres, M. F., et al. (2012). Lifestyle transitions in plant pathogenic Colletotrichum fungi deciphered by genome and transcriptome analyses. Nat. Genet. 44, 1060-1065. doi: $10.1038 /$ ng.2372

Qi, L., Kim, Y., Jiang, C., Li, Y., Peng, Y., and Xu, J.-R. (2015). Activation of Mst11 and feedback inhibition of germ tube growth in Magnaporthe oryzae. Mol. Plant Microbe Interact. 28, 881-891. doi: 10.1094/MPMI-12-14-0391-R

Rasmussen, J. B., and Hanau, R. M. (1989). Exogenous scytalone restores appressorial melanization and pathogenicity in albino mutants of Colletotrichum graminicola. Can. J. Plant Pathol. 11, 349-352. doi: 10.1080/07060668909501078

Ruiz-Roldan, M. C., Maier, F. J., and Schafer, W. (2001). PTK1, a mitogen activated-protein kinase gene, is required for conidiation, appressorium formation, and pathogenicity of Pyrenophora teres on barley. Mol. Plant Microbe Interact. 14, 116-125. doi: 10.1094/MPMI.2001.14.2.116

Sakaguchi, A., Tsuji, G., and Kubo, Y. (2010). A yeast STE11 homologue CoMEKK1 is essential for pathogenesis-related morphogenesis in Colletotrichum orbiculare. Mol. Plant Microbe Interact. 23, 1563-1572. doi: 10.1094/MPMI-03-10-0051

Sambrook, J., and Russell, D. W. (2001). Molecular Cloning: a Laboratory Manual, $3 r d$ Edn. Cold Spring Harbor, NY: Cold Spring Harbor Laboratory Press.

Takano, Y., Kikuchi, T., Kubo, Y., Hamer, J. E., Mise, K., and Furusawa, I. (2000). The Colletotrichum lagenarium MAP kinase gene CMK1 regulates diverse aspects of fungal pathogenesis. Mol. Plant Microbe Interact. 13, 374-383. doi: 10.1094/MPMI.2000.13.4.374

Takano, Y., Kubo, Y., Kuroda, I., and Furusawa, I. (1997). Temporal transcriptional pattern of three melanin biosynthesis genes, PKS1, SCD1, and THR1, in appressorium-differentiating and nondifferentiating conidia of Colletotrichum lagenarium. Appl. Environ. Microbiol. 63, 351-354.

Turrà, D., Segorbe, D., and Di Pietro, A. (2014). Protein kinases in plantpathogenic fungi: conserved regulators of infection. Annu. Rev. Phytopathol. 52, 267-288. doi: 10.1146/annurev-phyto-102313-050143
Ushimaru, T., Terada, H., Tsuboi, K., Kogou, Y., Sakaguchi, A., Tsuji, G., et al. (2010). Development of an efficient gene targeting system in Colletotrichum higginsianum using a non-homologous end-joining mutant and Agrobacterium tumefaciens-mediated gene transfer. Mol. Genet. Genomics. 284, 357-371. doi: 10.1007/s00438-010-0572-1

Valiante, V., Jain, R., Heinekamp, T., and Brakhage, A. A. (2009). The MpkA MAP kinase module regulates cell wall integrity signaling and pyomelanin formation in Aspergillus fumigatus. Fungal Genet. Biol. 46, 909-918. doi: 10.1016/j.fgb.2009.08.005

Wei, W., Zhu, W., Cheng, J., Xie, J., Jiang, D., Li, G., et al. (2016). Nox complex signal and MAPK cascade pathway are cross-linked and essential for pathogenicity and conidiation of mycoparasite Coniothyrium minitans. Sci. Rep. 6:24325. doi: 10.1038/srep24325

$\mathrm{Xu}$, J. R., and Hamer, J. E. (1996). MAP kinase and cAMP signaling regulate infection structure formation and pathogenic growth in the rice blast fungus Magnaporthe grisea. Genes. Dev. 10, 2696-2706. doi: 10.1101/gad.10.21. 2696

Yago, J. I., Lin, C. H., and Chung, K. R. (2011). The SLT2 mitogenactivated protein kinase-mediated signaling pathway governs conidiation, morphogenesis, fungal virulence and production of toxin and melanin in the tangerine pathotype of Alternaria alternata. Mol. Plant Pathol. 12, 653-665. doi: 10.1111/j.1364-3703.2010.00701.x

Yamauchi, J., Takayanagi, N., Komeda, K., Takano, Y., and Okuno, T. (2004). cAMP-pKA signaling regulates multiple steps of fungal infection cooperatively with Cmk1 MAP kinase in Colletotrichum lagenarium. Mol. Plant Microbe Interact. 17, 1355-1365. doi: 10.1094/MPMI.2004.17. 12.1355

Yin, Z., Tang, W., Wang, J., Liu, X., Yang, L., Gao, C., et al. (2016). Phosphodiesterase MoPdeH targets MoMckl of the conserved mitogenactivated protein (MAP) kinase signalling pathway to regulate cell wall integrity in rice blast fungus Magnaporthe oryzae. Mol. Plant Pathol. 17, 654-668. doi: 10.1111/mpp. 12317

Zeng, F., Gong, X., Hamid, M. I., Fu, Y., Jiatao, X., Cheng, J., et al. (2012). A fungal cell wall integrity-associated MAP kinase cascade in Coniothyrium minitans is required for conidiation and mycoparasitism. Fungal Genet. Biol. 49, 347-357. doi: 10.1016/j.fgb.2012.02.008

Zhang, S., Jiang, C., Zhang, Q., Qi, L., Li, C., and Xu, J. R. (2016). Thioredoxins are involved in the activation of the PMK1 MAP kinase pathway during appressorium penetration and invasive growth in Magnaporthe oryzae. Environ. Microbiol. doi: 10.1111/1462-2920.13315. [Epub ahead of print].

Zhang, X. R., Henriques, R., Lin, S. S., Niu, Q. W., and Chua, N. H. (2006). Agrobacterium-mediated transformation of Arabidopsis thaliana using the floral dip method. Nat. Protoc. 1, 1-6. doi: 10.1038/nprot. 2006.97

Zhao, X. H., Mehrabi, R., and Xu, J. R. (2007). Mitogen-activated protein kinase pathways and fungal pathogenesis. Eukaryotic Cell 6, 1701-1714. doi: 10.1128/EC.00216-07

Zheng, L., Campbell, M., Murray, J., Lam, S., and Xu, J. R. (2000). The $B M P 1$ gene is essential for pathogenicity in the gray mold fungus Botrytis cinerea. Mol. Plant Microbe Interact. 13, 724-732. doi: 10.1094/MPMI.2000. 13.7.724

Zhou, X., Zhang, H., Li, G., Shaw, B., and Xu, J. R. (2012). The Cyclaseassociated protein Capl is important for proper regulation of infectionrelated morphogenesis in Magnaporthe oryzae. PLoS Pathog. 8:e1002911. doi: 10.1371/journal.ppat.1002911

Conflict of Interest Statement: The authors declare that the research was conducted in the absence of any commercial or financial relationships that could be construed as a potential conflict of interest.

Copyright (c) 2016 Wei, Xiong, Zhu, Wang, Yang and Peng. This is an openaccess article distributed under the terms of the Creative Commons Attribution License (CC BY). The use, distribution or reproduction in other forums is permitted, provided the original author(s) or licensor are credited and that the original publication in this journal is cited, in accordance with accepted academic practice. No use, distribution or reproduction is permitted which does not comply with these terms. 